\title{
Study of the Electrochemical Passive-Active Transition of Chalcopyrite in Acidic Solution
}

\author{
Qingyou Liu ${ }^{1}$, Kai Zheng ${ }^{1,2}$, Xiaoying Wen ${ }^{1}$, Heping $L i^{1, *}$ \\ ${ }^{1}$ Institute of Geochemistry, Chinese Academy of Sciences, Guiyang 550002, China \\ ${ }^{2}$ University of Chinese Academy of Sciences, Beijing, 100039, China \\ *E-mail: liheping123@yahoo.com
}

doi: $10.20964 / 2016.08 .05$

Received: 28 March 2016/Accepted: 22 May 2016 / Published: 7 July 2016

The electrochemical behaviors of chalcopyrite in $1.0 \mathrm{M} \mathrm{H}_{2} \mathrm{SO}_{4}$ were studied by potentiodynamic polarization. The experimental results revealed that chalcopyrite has four different potential ranges: passive for OCP up to $500 \mathrm{mV}$; trans-passive dissolution/passive from $500 \mathrm{mV}$ to $780 \mathrm{mV}$; active from $780 \mathrm{mV}$ to $900 \mathrm{mV}$; and pseudo-passive above $900 \mathrm{mV}$. When the electrolyte contained $3.0 \mathrm{~g} / \mathrm{L} \mathrm{Fe}^{3+}$, the passive phenomenon weakened markedly, the trans-passive dissolution/passive range became narrower, the active potential sharply decreased, and the electrochemical promoting efficiency increased 34.86-fold. Electrochemical impedance spectroscopy (EIS) confirmed the potentiodynamic results, namely, that chalcopyrite is in a passive state at OCP and its charge transfer resistance $R_{\mathrm{SC}}$ and passive film resistance $R_{\mathrm{p}}$ are 816.5 and $18,722 \Omega \cdot \mathrm{cm}^{2}$, respectively. At a potential of $800 \mathrm{mV}$, the chalcopyrite $R_{\mathrm{SC}}$ decreased to $42.9 \Omega \cdot \mathrm{cm}^{2}$, and an equivalent inductance occurred. Passive film did not observed, which was also consistent with the electrode's active characterization. These results have direct implications for chalcopyrite hydrometallurgy.

Keywords: chalcopyrite; potentiodynamic curve; EIS; electrochemical dissolution

\section{$\underline{\text { FULLTEXT }}$}

(C) 2016 The Authors. Published by ESG (www.electrochemsci.org). This article is an open access article distributed under the terms and conditions of the Creative Commons Attribution license (http://creativecommons.org/licenses/by/4.0/). 